Revista Oficial del Poder Judicial

ÓRGANO DE INVESTIGACIÓN DE LA CORTE SUPREMA DE JUSTICIA DE LA REPÚBLICA DEL PERÚ

Vol. 13, n. ${ }^{\circ} 16$, julio-diciembre, 2021, 483-507

ISSN: 1997-6682 (Impreso)

ISSN: 2663-9130 (En Línea)

DOI: 10.35292/ropj.u13i16.469

\title{
El desarrollo de la lingüística contemporánea y su importancia en el derecho
}

The development of contemporary linguistics and its releuance to law

00

CARLOS MARÍA CÁRCOVA Universidad de Buenos Aires

(Buenos Aires, Argentina)

Contacto: cmcarcoua@derecho.uba.ar https://orcid.org/0000-0002-5906-5875

\section{RESUMEN}

Este texto se propone ofrecer a los operadores jurídicos un recorrido sintético del desarrollo de la lingüística. El objetivo es proveer una herramienta fundamental para la elucidación de problemas teóricos del derecho, teniendo en cuenta su aspecto lingüístico y semiótico.

Palabras clave: derecho y literatura; semiótica; teoría literaria; narratología. 


\section{ABSTRACT}

This text aims to offer legal operators a synthetic tour of the development of linguistics. The objective is to provide a fundamental tool for the elucidation of theoretical problems of Law, taking into account its linguistic and semiotic aspect.

Key words: law and literature; semiotics; literary theory; narratology.

Recibido: 17/10/2021 Aceptado: 15/11/2021

Este texto se propone ofrecer a los operadores jurídicos un recorrido sintético del desarrollo de la lingüística. Considero fundamental que los juristas se familiaricen con estas ideas, pues la materia prima con la que trabajan es el lenguaje, que está asociado a otras formas de comunicación social que también producen sentido y pueden ser abordadas desde la semiótica: togas, arquitecturas, reparto de los espacios, símbolos, embanderamientos y jerarquías. Los aportes contemporáneos de la lingüística y la semiótica son de vital importancia para el derecho por dos motivos: 1) constituyen una vía de elucidación de problemas teóricos del conocimiento jurídico; y 2) contribuyen a la reactivación de sus estudios.

\section{LA LINGÜÍSTICA COMO SABER AUTÓNOMO Y CENTRAL}

El lenguaje ha sido objeto de reflexión desde la más temprana filosofía. Sin embargo, solo a partir de mediados del siglo XX se ha transformado en un discurso central de la praxis humana interindividual. Wittgenstein, Lévi-Strauss, Heidegger, Merleau-Ponty, Derrida, entre muchos otros, dieron cuenta del modo en que el lenguaje sobredetermina pensamiento y vida al mismo tiempo.

Reconsiderado en su constitutiva importancia, el pensamiento filosófico, artístico, epistémico y científico es atravesado en la actualidad por el denominado «giro lingüístico». En efecto, la diversidad 
de lenguas y las dudas acerca de sus respectivas conmensurabilidades constituye un problema mayor. Las antiguas discusiones acerca de la naturalidad o la arbitrariedad de los significados (Cratilo) se han resuelto decididamente a favor de esta última. Como resulta conocida la relación entre el signo y su referencia, tematizada por la semiótica aparece con esta última designación, por primera vez, con John Locke (Ensayo sobre el entendimiento humano). Pero en la modernidad la semiótica dejó de ser un aspecto lateral de la reflexión filosófica para adquirir la forma de una disciplina autónoma que se ocupa - también autorreferencialmente-del lenguaje.

Este saber estilizado tiene ya un siglo de fructíferos y diversos desarrollos, si se toman como punto de partida las obras de los padres fundadores: el lingüista suizo Ferdinand de Saussure (18571913) y el pragmatista norteamericano Charles Sanders Peirce (1839-1914). Ambos trabajaron sin conocerse ni comunicarse. El primero denominó a la disciplina como semiología, y el segundo, como semiótica. Sus papeles fueron recopilados posteriormente por discípulos y alumnos. En Curso de lingüística general (1915), basado en conferencias de Saussure, aparece su definición ya clásica de semiología como ciencia que estudia la vida de los signos en el seno de una sociedad. En ella existen otros sistemas semiológicos y el lenguaje ocupa un lugar privilegiado. Por otro lado, para Peirce todo pensamiento y todo conocimiento refiere a los símbolos, que constituyen su entramado. A pesar del intento de establecer diversas diferencias entre esta clase de estudios, finalmente los términos semiología y semiótica se han usado como sinónimos o, al menos, como claramente intercambiables.

Los trabajos de Peirce fueron reunidos entre 1931 y 1935 en los llamados Collected Papers. Sostenía en ellos que el lenguaje constituía al ser humano, transformándolo en la suma total de sí mismo, $\mathrm{y}$ definiendo al signo como «algo que representa para alguien algo, en algún sentido o capacidad». Con esa formulación eludió, como 
sostuvo Eco, la intención subjetiva de la comunicación entre los seres humanos. Así, la semiosis (producción del significado) implicaba para Peirce tres entidades: el signo, su objeto y su interpretante. El objeto es lo que el signo representa, pero su interpretante no es un sujeto sino el "efecto mental» generado por la relación signo/objeto. Además, dado que la conversión de signo en interpretante no sucede en la mente sino en el sistema de signos, Peirce anticipaba la perspectiva posestructuralista de una semiosis ilimitada, que enlaza un signo a otro, sin dependencia directa al objeto o la referencia.

Por su parte, Saussure representa la tradición estructuralista de raigambre europea de la disciplina, que nació mostrando a la lengua como formadora de lo real y no tan solo como un acceso posible a lo real. Proponía un tipo de reflexión que se alejaba de lo histórico y temporal (Hegel, Marx y Darwin), distinguiendo entre lengua y habla. La lengua, es decir, las reglas sintácticas y las formas, no varían y son, por consiguiente, más importantes que los elementos que mutan y se transforman. De modo que privilegia lo «estructural sincrónico» por sobre lo «cambiante y diacrónico».

Su posición, como se verá, respondía a un clima de época y fue cuestionada desde diversas perspectivas, entre otras por las de quienes opinaban que lo sincrónico y lo diacrónico se coimplican. En esa línea, Fredric Jameson sostuvo que la visión estructuralista de Saussure obstaba a la percepción de los cambios históricos que también producen impacto en el lenguaje. Por otra parte, tanto las intervenciones de la Escuela de Praga como las del Círculo de Bajtín, más tarde, intentaron cerrar la grieta entre uno y otro extremo de esa polaridad.

Saussure había concebido a la investigación lingüística como la manera de entender los procesos abstractos de una lengua, sus unidades y sus combinatorias, más que trazar su historia o describir 
actos individuales de habla. También definió al signo en sus dos dimensiones: una forma que significa, el significante, y una idea significada, el significado.

El lema no posee naturaleza referencial. La voz «león» refiere a una representación mental, no a un animal. Por eso, expresiones como «pero» o «sin embargo» no implican ni siquiera la representación mental. La relación entre significante y significado es arbitraria, y no hay relación analógica (ni ontológica) entre uno y otro. Cada lengua, además, crea sentido mediante distintos encadenamientos entre sonido y significado. Por eso no se puede traducir palabra por palabra.

El signo es social y existe pragmáticamente para cada grupo de usuarios. Las relaciones de los signos pueden ser pragmáticas: unidades que se asocian (por ejemplo, letras que se eligen); o sintagmáticas: secuencias del habla (sintagmas que se combinan). Barthes propuso el ejemplo de la ingesta: el sujeto elige un fiambre entre varios y lo acompaña (combina) luego con un asado al horno.

\section{EL FORMALISMO RUSO}

Aun antes de la Revolución, para 1915, ya se hallaba en desarrollo en Rusia una importante corriente de pensamiento que ponía su atención en el uso de la lengua y la estructura de los relatos o las narraciones. Muchos fueron los nombres relevantes, entre ellos Vladimir Propp, Viktor Shklovsky, Roman Jakobson (más tarde fundador de la Escuela de Praga) y varios más que se mencionarán oportunamente. En general, buscaron las propiedades inmanentes de la literatura, sus estructuras y sistemas, que imaginaron como independientes de otros órdenes de la cultura y la sociedad. Su objeto era la literaturidad, es decir, aquello que hace de cierto texto un producto literario. 
Shklovsky tuvo gran influencia y un pensamiento de avanzada. Distinguía el lenguaje poético del práctico. El primero solo servía para interrumpir y distorsionar la percepción rutinaria, que era, precisamente, el propósito mismo del arte: destituir lo habitual, lo repetido, lo previsible. Estaban animados por un propósito esteticista (desfamiliarizar) que luego retomaría Brecht para atribuirle una función diferente: denunciar la alienación a través de una obra de arte conscientemente política, que mostrara su propio proceso de producción. Claro que, a diferencia de Brecht, los formalistas fueron solo esteticistas y procuraron siempre exponer los mecanismos empleados para la disposición y el procesamiento de la textualidad. El arte aparecía así como un sistema de signos y convenciones, más que como registro de fenómenos naturales o sociales.

Uno de los integrantes más notorios de este movimiento del formalismo ruso, que décadas más tarde quedaría estrechamente vinculado con la corriente estructuralista, fue Mijaíl Bajtín, quien tuvo como discípulos, entre otros, a Tzvetan Todorov y Julia Kristeva, integrantes de su círculo. En el último período del formalismo, Bajtín profundizó el tenor crítico de sus posiciones, poniendo en crisis las ideas de Saussure y sus dicotomías básicas: lengua y habla, y sincrónico y diacrónico. Reivindicó el valor del habla como producto propio de la interacción social, caracterizando con acritud la sincronía como una especie de necrofilia que implica nostalgia por las lenguas muertas, fenómeno al que llama «objetivismo abstracto».

Saussure, como heredero de Descartes y Leibniz, enfatizó las características fonéticas y léxicas de la invariancia que permite la formulación de códigos. Bajtín, en cambio, creía que el lenguaje vive en la heterogeneidad y el desorden y, por tanto, la estabilidad del signo es una mistificación del objetivismo, ya que lo propio del lenguaje es la multiplicidad de significados animados por lo social y lo histórico. El signo se transforma así en un objeto de lucha 
para la construcción del sentido. Él llamó a ese fenómeno «multiacentualidad». Tuvo con el formalismo acuerdos, reconocimientos y confrontaciones. Pero a pesar de sostener una concepción marxista, no vinculó el lenguaje a cuestiones de clase y economía, sino a un papel específico del arte vinculado con aquella idea de «desfamiliarización».

\section{EL ESTRUCTURALISMO DE PRAGA}

La llegada al poder de Stalin en la URSS resultó negativa para los semiólogos, mientras que en Praga se reorganizó un potente movimiento, que tuvo a la cabeza a Jakobson, Tinianov y Mukařovský. Los dos primeros trabajaron con la textualidad, pero también con el cine, el teatro y la pintura. El último, más cerca de la crítica bajtiana, pensaba que el contexto total de los fenómenos sociales (filosofía, política, religión y economía) construye la realidad que el arte representa.

Entre los aportes de Jakobson, cabe evocar la distinción que planteó entre fonética, en tanto sonidos que produce el habla, y fonología, consistente en el estudio del sonido que produce efectos diferenciales destinados a generar significado, desempeñando un papel en la comunicación. Jakobson sostuvo que en la variedad de sonidos de las lenguas naturales se daban oposiciones binarias de tipo fonológico, constituyendo rasgos distintivos, por ejemplo: nasalización/vibración de cuerdas vocales, postura labial, etc. Y clasificó doce oposiciones de esta índole. Esa tarea permitió a la lingüística reducir la caótica heterogeneidad del contínuum del habla. En su momento, Lévi-Strauss se apoyó en ese análisis para el desarrollo de su antropología estructural.

\subsection{Jakobson y el esquema comunicativo}

El autor que analizamos, con la finalidad de distinguir el uso poético de otros usos del lenguaje, propuso un esquema de la comunicación 
que devino canónico y suele aludirse bajo la denominación de «modelo del tubo». Distinguió seis partes: emisor, receptor, mensaje, código (debe ser compartido), canal («tubo» a través del cual circula el mensaje, por ejemplo, interlocución, correo, etc.) y contexto (opera como sistema articulado de referencias, por ejemplo, la comunicación en el ámbito de la navegación, la guerra o una filmación, etc.). La unión articulada acertadamente de estos elementos produce significación.

Por otra parte, en la comunicación pueden enfatizarse cualquiera de estos elementos, lo que implicará la posibilidad de distinguir el tipo de función que la comunicación está destinada a cumplir. La «función emotiva» hace pie en el emisor; la «función conativa»se refiere al receptor en tanto destinatario (órdenes y prohibiciones); la «función fáctica» corresponde al canal a través del cual se establece el contacto: se trata de las interjecciones rituales, como «bien», «por cierto»y «habitualmente», utilizadas para abrir la comunicación y facilitarla; la «función referencial» se refiere al contexto; y la «función poética» es aislada y distinguida por Jakobson en función de los límites autorreferenciales del signo que le dan textura al mensaje. Lecturas más sociales de lo lingüístico, como las de Bajtín o las de la escuela de Praga, criticarían esta mirada. Por último, la «función metalingüística» se concreta cuando el lenguaje reflexiona sobre sí mismo. Mientras que en las tesis de Jakobson se destaca el papel del emisor y la función emotiva del arte, marxistas, feministas y realistas en general destacan la del contexto. El formalismo enfatiza el mensaje; la semiótica, el código; la teoría de la recepción, el texto; y las corrientes psicoanalíticas, el receptor.

\section{EL ESTRUCTURALISMO}

Constituyó un movimiento de gran importancia y a partir de su origen saussuriano se extendió a otras disciplinas y ámbitos del saber. Para Roland Barthes se trató de «un modo de análisis de los 
artefactos culturales que se originan en la lingüística contemporánea». Para Jean Piaget, de un método de investigación basado en principios de totalidad, transformación y autorregulación. En términos generales se lo ha caracterizado como un entramado teórico a través del cual la conducta, las instituciones y los textos se suponen analizables según una red de relaciones subyacentes, cuyos elementos obtienen su significado por la relación que establecen con otros elementos de la red. Para decirlo con un ejemplo, el significado de una obra pictórica como La Gioconda debe buscarse más que en la historia y verdadera identidad del/la modelo, o en la biografía de Da Vinci, en la peculiar relación de los colores, las perspectivas, los volúmenes y las imágenes de la obra.

Posiblemente sea Lévi-Strauss quien utilizó la concepción estructuralista con mayor audacia e impacto en el campo de los fenómenos sociales, mentales y artísticos. No son, pensaba, los elementos aislados de un cierto fenómeno los que le adjudican sentido, sino el modo en que se encuentran combinados en su interior. Un mito en particular solo puede ser comprendido cuando se lo relaciona con otros mitos de la misma cultura.

Como es conocido, Saussure también dio fundamento al desarrollo de una semiología narrativa (o narratología). Claude LéviStrauss y Algirdas Greimas procuraron esclarecer la matriz generativa de los relatos con el propósito de encontrar modelos universales. Esa clase de estudios ya habían sido iniciados en 1929 por Valentín Propp. En Morfología del cuento, postulaba una visión diacrónica de relato-estructura, que sin embargo distinguía treinta y un invariantes en las sagas infantiles populares: villanos, mediación, incidente conector, etc. Pensó que allí se situaba la estructura profunda del relato popular. Los estructuralistas, por su parte, intentaron reducir el número de invariantes mediante modelos sincrónicos de oposición, no dependientes de una secuencia uniforme de hechos. Veían en ello una especie de ADN del relato. Tales ideas convocaron 
la atención de intelectuales de gran relevancia, que pasaron a ser defensores y representantes de las tesis del estructuralismo, como Barthes, Todorov, Genette, Lacan, entre muchos otros.

La corriente en análisis adquirió durante las décadas de los sesenta y setenta del siglo XX un lugar dominante en los más diversos ámbitos. La ropa que un sujeto elige para vestir y el modo en que ingresa a una cena, decía Roland Barthes, presuponen un sistema que entrama las significaciones sociales. Para Jacques Lacan el inconsciente debe ser pensado como lenguaje. Louis Althusser produjo una importante renovación del pensamiento marxista y marxiano proponiendo una lectura estructuralista del materialismo histórico en general y de El Capital en particular, y redefiniendo la «ideología» como la relación imaginaria de los individuos con sus condiciones reales de existencia. Con ello, el orden social aparece como el agente que ordena y reproduce esa existencia. En Teoría de la Semiótica, Umberto Eco define el campo concernido como aquel que comprende desde la narratología hasta la zoosemiótica (conducta comunicativa de los seres vivos no humanos), pasando por la kinésica y la prosémica, códigos culturales que tienen que ver, respectivamente, con el movimiento humano y la proximidad, además de la teoría textual, los alfabetos desconocidos, los códigos secretos y la semiótica médica. Al mismo tiempo, la moda, el gusto, la cocina, los cómics, el cine y la literatura (Alain Resnais, Alain Robbe-Grillet, Marguerite Duras, etc.). Sin embargo, como otros tantos movimientos culturales, el estructuralismo cumplió también su ciclo y llego a su cenit.

\section{EL POSESTRUCTURALISMO}

Esta corriente nació a partir de la divulgación de los trabajos de Jacques Derrida y sus tesis deconstruccionistas, las que constituían una abierta crítica a la corriente antes mencionada. Se proponía 
confrontar la idea de sistematicidad y permanencia que implicaba el estructuralismo, en razón de lo que ella terminaba por dejar afuera, por excluir de la reflexión. De modo que este modelo crítico implicó un deslizamiento de la importancia atribuida al significado, a favor de un papel más significativo puesto en el significante; un deslizamiento de la importancia de la expresión a la de la enunciación; de la relevancia de lo espacial a la de lo temporal; y, por decirlo de algún modo, de la estructura a la «estructuración», es decir, al proceso que la conforma.

Derrida sostenía que los metalenguajes no pueden evitar la diseminación lingüística y textual. Los signos se mueven hacia afuera, en dirección a otros contextos de significación, resistiendo entonces la clausura sistémica, en una sucesión de continua reescritura y proliferación de referencias, de texto a texto, es decir, de «intertextualidad». Esta postura supone controvertir algunas nociones fuertes de la tradición estructuralista: la estabilidad del signo, y la idea de sujeto unificado, de identidad y de verdad. La aludida intertextualidad implica una multiplicidad de resignificaciones. Derrida condenaba el logocentrismo saussuriano, al cual veía como una idea esencialista que presupone la existencia del significado con independencia de las estructuras del lenguaje. Es decir, el significado tendría su origen en la realidad y no en los juegos de lenguaje. Del mismo modo, condenaba el «fonocentrismo», que supone que los fonemas representan significados presentes en la conciencia del hablante, constituyendo la escritura un segundo grado de mediación. Para el autor, la escritura no es una forma subsidiaria de la expresión hablada. Por el contrario, ponía en juego la noción de "archiescritura», en la que la escritura se convierte en el modelo de todas las operaciones lingüísticas. Frente a las tesis saussorianas, proponía una "gramatología» que estudiaría por un lado la escritura y, por el otro, la textualidad en general. 


\section{ALGUNAS NOCIONES OPERATIVAS}

\subsection{La intertextualidad}

Para Julia Kristeva los discursos artísticos (literarios, fílmicos y pictóricos) debían caracterizarse como prácticas significantes de características diferenciales. Como prácticas articuladas de procesos de transformación de una materia prima determinada en un cierto producto (Louis Althusser). El texto es definido como "productividad», idea que engloba al productor y al lector/espectador bajo la forma de una reconstrucción de la sistematicidad y la función comunicativa. Llamó a esto signifiance.

La autora tradujo al término «intertextualidad» analizado aquí, el concepto de Bajtín de «dialoguismo» o "polifonía», entendido como la relación de cualquier expresión con otras expresiones. El concepto sugiere que cada texto forma una intersección de superficies textuales. Es decir, posibilidades infinitas y siempre abiertas, generadas por todas las prácticas discursivas de una cultura.

Tanto para Bajtín como para Kristeva, su discípula, todo texto constituye un mosaico de citas, un "palimpsesto de huellas». No se trata de la influencia de un autor sobre otro, sino de la trasposición de un sistema de signos en otro, a partir de nuevas articulaciones denotativas y connotativas. También Lévi-Strauss, en sus estudios antropológicos, descubrió el valor del intertexto. Sostenía que un mito concreto solo podía ser comprendido por su relación con un sistema de otros mitos, prácticas y códigos culturales. Umberto Eco, por su lado, hablaba de marcos intertextuales que orientan la representación del lector y llenan vacíos.

Decía Bajtín que los tesoros semánticos que Shakespeare incorporó en sus obras fueron creados y recogidos a lo largo de los siglos, permaneciendo a veces ocultos en el lenguaje, en la comunicación hablada, en tramas que se remontan a la antigüedad clásica, muchas veces ocultas en las formas de pensar. En esa línea, el dialoguismo 
rechaza los paradigmas formalistas de la teoría lingüística, tanto como los sociológicos que solo rescatan lo biográfico o lo ideológico.

\subsection{La transtextualidad}

Basándose en Bajtín y en Kristeva, Gérard Genette (Palimpsestos, 1982) propuso un término más abierto e inclusivo, transtextualidad, como la relación entre un texto con otros, de forma manifiesta o secreta. Restringía la intertextualidad a una copresencia efectiva de dos textos bajo las formas de cita, plagio o alusión. A su vez, sugirió otras relaciones: la paratextualidad, es decir, la relación entre el texto y los títulos, los prefacios, los posfacios, los epígrafes, las dedicatorias, las instrucciones, las tapas, etc., o, en otras palabras, los mensajes y los accesorios que rodean al texto; la metatextualidad, que consiste en la crítica de un texto respecto de otro, tanto de forma explícita como implícita; la architextualidad, que se refiere a la taxonomía que encasilla un texto, pacífica o controversialmente, a partir de sus títulos o subtítulos (por ejemplo, «Tragedia en dos actos»); y, por último, la hipertextualidad, que es la relación de un texto (hipertexto) con un texto anterior (hipotexto), que el primero transforma o modifica, reelabora o altera (la Odisea o Hamlet, que inspiran e influyen en el Ulyses de Joyce). En esa línea, Genette mencionó Sueños de un seductor (Play It Again, Sam) de Herbert Ross y Woody Allen. El título funciona en su versión original inglesa, decía, como un contrato de hipertextualidad cinemática, en relación con Casablanca.

\subsection{El discurso}

En términos tradicionales, la idea de «discurso» estaba asociada a la exposición ordenada en el habla o la escritura de un tema determinado. En el período semiótico, particularmente con la llegada del estructuralismo, la palabra pasó a ser empleada por disciplinas 
diferentes en el contexto de variadas investigaciones. La lingüística, en una acepción amplia, designa a cualquier uso organizado del lenguaje, más allá de la frase. Puede referirse a distintos actos de habla (conversación, poema, charla, sermón, entrevista, etc.). Benveniste enfatizaba la naturaleza interrelacional del discurso (por ejemplo, la palabra "yo» solo adquiere sentido dentro de las circunstancias efímeras del discurso). El hablante, en un momento determinado, se transforma en el oyente, en el siguiente momento. Este autor distinguió entre histoire y discours. En la primera la verbalización carece de las marcas de la comunicación; en la segunda tales marcas se encuentran presentes.

Por su parte, la sociolingüística estudia la inscripción de los actos de habla en una formación sociocultural determinada, mientras que el denominado análisis del discurso se preocupa por descubrir las regularidades lingüísticas al interior del discurso (por ejemplo, su coherencia). En la vertiente más politizada (Pêcheux y Halliday) se muestra cómo las disposiciones asimétricas de poder operan sobre el uso cotidiano de la lengua, reforzando desigualdades opuestas que se negocian dentro del lenguaje.

Michel Foucault usó la noción con un sentido peculiar: más que un sistema sígnico, el discurso se expresa inscripto en la cultura, una constitución social de lugares de poder, especialmente al interior de los lenguajes especializados e institucionalizados. Los regímenes discursivos constituyen procesos, aparatos, procedimientos mediante los cuales se producen la verdad y el conocimiento. La verdad no es más que un constructo usado y explotado por grupos en lucha. Esta noción des-subjetiviza el discurso y lo inordena en procesos históricos. Para este autor, el poder - aquí se separa del marxismo- se entiende mejor en la micropolítica de las redes que entraman prácticas e instituciones, que en el análisis macropolítico acerca del Estado y las clases sociales. 


\section{ESTUDIOS SOBRE LA NARRATIVIDAD}

Los seres humanos utilizan el lenguaje para organizar su experiencia y representar el mundo que comparten. Asimismo, las diversas estructuras lingüísticas están vinculadas a las formalidades y los usos de la comunicación. Tales finalidades implican modos de organización del discurso que constituyen criterios cognitivos para representar el mundo. Narrar es uno de ellos. Sin embargo, narrar no significa reflejar cierta realidad sino más bien construirla y evaluarla. No es tarea neutral e implica orientar la cognición del receptor.

En los pliegues de la existencia los seres humanos tejen historias acerca de lo ya acontecido o lo que podría acontecer, dándole sentido a aquella. En síntesis, la narración supone un modo de conocimiento, un modo de ordenar la experiencia. El discurso argumentativo o expositivo recurre con frecuencia a la narración para tornarse más accesible. La cultura de una comunidad radica en la capacidad de que dispone para comunicar la experiencia en forma narrativa y construir de ese modo una identidad propia que devendrá canónica. Las narraciones pueden adquirir diversas formas: íconos, imágenes, diseños, fotos, textos, canciones, filmaciones, anécdotas, sátiras, chistes, crónicas, mitos y casos.

Nacemos siendo recipiendarios de relatos. A través de ellos aprendemos el lenguaje y socializamos, es decir, nos afiliamos a un grupo. Antes de conocer de argumentos, intuitivamente usamos los relatos y demandamos historias de nuestros padres. Por ello, la narración ha sido estudiada y observada desde épocas lejanas. Desde la mímesis aristotélica de La Poética hasta los diversos enfoques desarrollados en el siglo XX: el lingüístico-semiológico, el fenomenológico-hermenéutico, el sociológico o el psicoanalítico, entre otros.

Distinguir y describir la actividad narrativa transforma al lector ingenuo en un lector crítico. Los diversos enfoques de la crítica no 
son de suyo excluyentes y pueden, por tanto, actuar complementariamente. En lo anterior se ha visto cómo, a partir de la mímesis aristotélica que presuponía en el lenguaje una forma de representación del mundo, fueron los importantes aportes del formalismo ruso a los estudios lingüísticos, recién en los albores del siglo $\mathrm{XX}$, los que provocaron su enorme desarrollo y el interés despertado en ámbitos científicos y filosóficos. Como se recuerda, el objeto de esta corriente y las que la continuaron era el fenómeno de la «literaturalidad» o «literariedad» (por ejemplo, «El arte como artificio» de Viktor Shklovsky), y el recurso empleado, el del extrañamiento o la "desfamiliarización», un proceso por el cual se intentaba interrumpir el automatismo de la percepción para demorarla en una mirada más atenta y más crítica (por ejemplo, describir un rostro como si fuera un territorio). Así, el arte mantiene una dinámica evolutiva de ruptura y sustitución.

En ese contexto, la «narratología» se propone como el estudio de la estructura interna del relato literario, a través de una gramática del texto de validez universal. Recogiendo los aportes del formalismo, el estructuralismo avanzó en la teorización narrativa. El primer Barthes, uno de sus conspicuos representantes, pudo advertir que el límite del análisis no estaba en la estructura de la frase, como se había pensado, sino en la forma en que diferentes frases se combinaban y ligaban en tanto elementos del texto. Pudo estudiar lo que denominó funciones distribucionales, que implicaban distinguir entre los «nudos» o núcleos del relato y otros elementos más circunstanciales (catálisis), que solo llenan los espacios existentes entre los nudos. Los núcleos organizan y denuncian el relato: encuentro, pelea, policía y detención. Por otro lado, la catálisis consiste en mecanismos para hacer avanzar y al mismo tiempo completar el relato: lluvia, frío, iluminación y vehículo.

A su tiempo, Algirdas Greimas abordó el relato, no en términos de las acciones cumplidas sino de sus agentes, a los que llamó «actantes». Propuso, pues, un modelo actancial. Los actos (actantes) 
no son necesariamente humanos. Lo fundamental, entonces, no consiste en los acontecimientos ni en los actores concretos, sino en los sistemas de valores que se enfrentan, y que el semiólogo debe encontrar no en la superficie narrativa, sino en su estructura profunda. Importa más lo que el personaje hace, que lo que dice.

\subsection{Los elementos que la narratología aporta al análisis del relato}

Con diversas denominaciones, los autores han coincidido en distinguir entre historia y trama en el relato. La primera remite a una sucesión encadenada de hechos referidos en el relato; la segunda, a la estrategia a través de la cual esos hechos se articulan, ordenan y presentan en la estrategia narrativa. Por su parte, Gerard Genette replanteó la distinción, diferenciando tres instancias: la de la historia o diégesis, como acontecimientos objeto del discurso; la narración, que es la relación establecida entre el narrador y el narratario; y el relato o discurso narrativo que, por diversos medios, orales o escritos, nos permite conocer la historia. Así, distinguió entre relatos referenciales (acontecimientos ocurridos, crónicas e historiografía) y relatos literarios (construcciones ficcionales).

En relación con el rol del tiempo en el relato, Genette dejó interesantes aportes. La pluridimensionalidad de los acontecimientos es dificultosamente captada por la implacable linealidad de la escritura o de la transmisión oral. Dos hechos ocurridos al mismo tiempo no pueden ser narrados sino en secuencia, lo que implica prelación, orden, etc., «construido» en el relato y no necesariamente existente en la realidad a la que este se refiere (cuando se trata de relatos referenciales).

El autor propuso una doble articulación: 1) la del tiempo del relato con la historia; y 2) la del tiempo del relato con la narración. Existe el orden de los acontecimientos en la historia y el orden seudotemporal de la disposición de los mismos en el relato. Debe 
atenderse entonces, al orden, la duración y la frecuencia de los acontecimientos en el relato para explicarnos sus posibles alteraciones o cambios al interior de su trama.

En este registro también resulta relevante el orden del relato, en definitiva propuesto por el narrador, a veces con fidelidad cronológica a los hechos, otras, manipulándolos expresivamente. Esta disponibilidad del tiempo y del orden del relato por el narrador constituye el eje de las teorías de Paul Ricoeur, como apreciaremos en otro apartado.

Gerard Genette ha estudiado también el modo del relato, básicamente constituido por dos factores: la distancia y la perspectiva. En relación con la primera, distingue tres tipos de discurso: el narrativizado, en el cual se borran las huellas de la enunciación; el transpuesto, en el cual el narrador incorpora los dichos de otros a su propio discurso; y el indirecto libre, en el que se mezclan los discursos del narrador y del personaje. En lo que concierne a la perspectiva, decía Genette que está siempre presente para darle sentido a los hechos. Adviértase que el ángulo desde el cual se observa o se narra no solo es de naturaleza visual (geométrica), sino también de naturaleza axiológica.

El narrador introduce perspectiva 1) desde el campo visual o lugar de la observación; 2) con el tono que elige (irónico o ingenuo); 3) con su elección moral (condena o comprensión); y 4) con su estimación veredictiva (duda, certeza o incredulidad). No puede olvidarse en esta reflexión que, desde Einstein, la realidad no es más que la apariencia que percibe el observador. La misma idea aparece en las construcciones sistémicas (Bertalanffy, Glasserman y Luhmann) y tiene resonancias más filosóficas en las tesis husserlianas acerca de la perspectiva y la socialización, que en el plano de la epistemología de las ciencias sociales que recogiera Alfred Schütz. En definitiva, la verdad resulta de la confrontación/articulación de diversas miradas. 
Por último, la narración posee un tiempo propio que no siempre es el mismo. Cuando decimos que es ulterior, establecemos un orden temporal entre el suceso y el relato que lo refiere; cuando decimos que es simultáneo, se describe el hecho que está acaeciendo; cuando afirmamos que es anterior, el relato se anticipa usando los verbos en futuro («la muerte llegará mansamente, a las seis en punto de la mañana»).

\section{OTROS ENFOQUES DE LA NARRACIÓN}

Desde 1960 fue tan importante el impacto del giro lingüístico y sus aportes, recogidos en tan diversos ámbitos disciplinarios, que ha debido concluirse que los fenómenos de los que se ocupa ya no son campo exclusivo de la semiología.

\subsection{La teoría narrativa}

También abordada por la ciencia cognitiva y la inteligencia artificial, que proponen un cierto sistema de reglas para describir regularidades en la estructura de las historias. Con ello se avanzó en la hipótesis de la existencia de una estructura mental global, como propia de culturas determinadas, para interpretar y reordenar el material de la intriga (Kintsch y Van Dijk). La estructura compartida por el narrador y el narratario permite la comprensión de un texto.

\subsection{La sociolingüística}

Se ocupa de los usos de la narrativa (Labov) utilizando métodos de la etnografía. El sentido del relato y su valoración (por qué se cuenta y con qué fin) responden a una significación en el contexto. Se torna decisiva la intención (dato prelingüístico) de los hablantes para entender el sentido de la narración. 


\subsection{La estética de la recepción}

Ha jugado un importante papel en este itinerario. En contraposición con el estructuralismo, desplaza la atención en el texto del sistema de signos hacia el lector. El esquema lingüístico es reemplazado por otro de tipo fenomenológico-hermenéutico. Para la fenomenología, el objeto existe en la medida que alguien lo percibe, se sostiene en esa saga en que la obra literaria o artística en general se constituye fundamentalmente sobre la base del acto de su recepción.

Wolfgang Iser propone que la obra de arte tiene dos polos: el artístico, creado por el autor; y el estético, que concretiza el receptor. Por consiguiente, la obra se situaría entre ambos. El sentido de esta (ni estático ni arbitrario) se produce en esa equilibrada convergencia. En la vaguedad del texto se sitúa la intervención activa del lector. Repone así el lugar del sujeto. También Paul Ricoeur reconoce que, aunque el texto tiene estructura y sentido, encuentra significado en el cruce con el mundo del lector. El texto - dice Ricoeursolo se hace obra en su intersección con el receptor.

\subsection{El discurso histórico}

En él, lo narrativo cumple una función cognoscitiva. Hayden White lideró una nueva mirada sobre el discurso historiográfico, descartando su predicada transparencia. También ese discurso se construye desde perspectivas y miradas, desde una cierta interpretación del mundo acorde con la de otros (Clifford Geertz). El interés por la narrativa impactó en los estudios antropológicos y etnográficos, precisamente de autores como Clifford Geertz o Margaret Mead, entre otros muchos.

William John Thomas Mitchell publicó en 1981 la obra titulada On Narrative, con artículos de personajes tan destacados como Jacques Derrida, Frank Kermode, Hayden White, Ursula Le Guin y Paul Ricoeur, entre otros. Todos enfatizaban el valor de lo narrativo 
en distintas disciplinas, que consiste, básicamente, en la posibilidad de los sujetos de representarse y estructurar el mundo. Como decía Hayden White, los hechos en sí no constituyen un relato, sino solo cuando se les organiza y otorga secuencialidad. Por lo tanto, como sostenía Northrop Frye, el historiador no se limita a contar una historia, sino a transformar un conjunto de acontecimientos en una unidad de sentido.

En esta línea se destaca también Jerome Bruner, quien defendía la existencia de dos modalidades complementarias de funcionamiento cognitivo: narrar y argumentar. Del mismo modo, decía Ricoeur, la narración constituye un modo de conocimiento que no se limita a la configuración que le es propia, pues incluye el proceso de lectura o refiguración del texto por parte del lector, que es un sujeto que lee $y$, por ello, conoce el mundo.

\subsection{La ficción}

Suele definirse como un enunciado falso cuyo valor de verdad (es decir, su falsedad) reconocemos. Sin embargo, no por ello los enunciados de esa índole resultan inservibles. No lo son ni siquiera cuando cumplen una función heurística en el camino hacia la verdad. O sea, cuando nos permiten mediante aproximaciones sucesivas pasar de una descripción imperfecta, nebulosa y desajustada a la construcción final de una verdad. Ahora, lo ficcional y lo real se encuentran francamente vinculados, en tanto lo primero puede presentarse como mímesis, reflejo y parábola acerca de lo segundo.

Si ese juego es conocido en el proceso de interlocución, entonces la ficción ni engaña ni miente. Se «administra» en una situación comunicativa en la que media impacto entre el emisor y el receptor, a través del cual este último puede enriquecer su comprensión del mundo mediante narraciones que guardan similitud (no correspondencia) con el mundo. De este modo aprenden los niños: al actuar roles figurados se socializan y toman conciencia cognitiva de la realidad en la que se encuentran. 
El teatro, la literatura y el cine refieren a la realidad a través de ficciones, y su capacidad de dar cuenta de ella es, frecuentemente, más amplia y más profunda que la de muchos discursos veritativos. La ficción impone sus propias reglas, que son las del "como sí», que suspenden provisoriamente, las que valen fuera del espacio lúdico (Flein). Pero la ficción se diferencia de la ensoñación, el engaño y la mentira, tanto como del mito, ya que la adhesión a ella es libre y limitada temporal y espacialmente, y solo pretende transgredir el límite de lo real. El instrumento para ello es el lenguaje, a través del cual se explora lo real desde el territorio de lo imaginario. Especialmente ilustrativo en este aspecto resulta el párrafo final de Jorge Luis Borges (1974) en su relato «Emma Zunz»:

La historia era increíble, en efecto, pero se impuso a todos, porque sustancialmente era cierta. Verdadero era el tono de Emma Zunz, verdadero el pudor, verdadero el odio. Verdadero también el ultraje que había padecido; solo eran falsas las circunstancias, la hora y uno o dos nombres propios (p. 568).

En el cruce entre lo real y lo imaginario se asienta la ficción. Como decía Ricoeur, tanto la historia como la ficción tienen una referencia común, precisamente el fondo temporal de la existencia humana. Solo la historia parece referirse a lo real, pero se trata de un «real pasado» al cual el historiador en su obra o el juez en el proceso pueden referirse de manera indirecta, configurando las tramas que los documentos o los testimonios autorizan o prohíben, pero jamás contienen. Esas tramas que combinan conformidad documental y coherencia narrativa son siempre «interpretación».

Si la ciencia intenta construir un mundo que permanezca invariable a pesar de la conflictividad humana (pretensión que actualmente también ha abandonado a través de la aceptación de la complejidad, la incertidumbre y el caos), la narrativa, en cambio, tiene como objetivo comprender los acontecimientos humanos para reconocer eventuales alternativas. 


\section{PAUL RICOEUR Y LA TRIPLE MÍMESIS}

La narración parte de la experiencia de la vida cotidiana que existe antes de ser contada. Es decir, las cosas acontecen antes de que alguien las refiera, de modo que poseen una "prefiguración» en el campo de la praxis. Ricoeur denominó mímesis I a esa prefiguración, que debe entenderse como una precomprensión de la vida cotidiana que distingue la acción del mero movimiento físico. La primera, como lo expuso Weber, está teleológicamente cargada, es decir, orientada a obtener cierta finalidad. En el relato, el narrador y su auditorio comparten esa precomprensión y se encuentran en capacidad de actualizar sus términos, de enlazarlos de modo que alcancen una efectiva significación.

Las formas simbólicas que regulan la comunicación social permiten "configurar» la experiencia a partir de esquemas narrativos reconocidos por el lector/oyente. Ese proceso de configuración que Ricoeur denominó mímesis II, de sintetizar experiencias diversas y componer elementos, autoriza a pasar de la sucesión de acontecimientos en que una historia consiste a una totalidad de sentido, de la que surge el «tema» que le brinda unidad y determina el punto final ${ }^{1}$. Ahí la configuración (organización de la trama), en la narración, sea esta referencial o ficcional, produce la mediación entre el antes y el después, entre la sucesión de hechos y su comprensión como un todo.

Ricoeur postuló una analogía entre la teoría del relato y la teoría de la metáfora, pues ambas permiten el acercamiento y producen sentido acerca de la realidad a la que aluden. La ficción narrativa refleja miméticamente la realidad y en paralelo la describe metafóricamente. Tanto el relato histórico como el ficcional tienen

1 Resulta interesante recordar que Lacan sostuvo que el punto final de un relato, al que llama punto de almohadillado o de capitoné, según las traducciones, otorga sentido a la totalidad de lo narrado. 
una dimensión cronológica y otra lógica y atemporal. La primera secuencia la historia y la segunda le atribuye el carácter de una totalidad significante. Conocer la trama, de este modo, permite hacer inteligible lo que puede aparecer como puramente accidental. El episodio que coloca al hombre al borde del abismo de su existencia, que le resulta incomprensible, genera relato. A través de este, lo imprevisto y circunstancial se transforma en destino.

Finalmente, Ricoeur atribuyó a la última etapa del proceso narrativo el nombre de mímesis III o refiguración. El final de una historia no puede ser deducido ni predecido. Sin embargo, las acciones, los pensamientos y los sentimientos que la constituyen, se dirigen necesariamente hacia él. Desde el final, en mirada retrospectiva comprendemos que las acciones conducían inexorablemente en su dirección. Toda ficción maneja su propia retórica de persuasión, en función de la cual el receptor acepta la propuesta del texto. La realidad del lector se transforma, se enriquece, se torna más profunda, más pintoresca o más inquietante. Es decir, se refigura el lector, el sujeto real, quien se enriquece con la experiencia del héroe real o ficticio mediante la lectura. La refiguración es posterior a la configuración y supone un modo de representarse el mundo de otros. La mímesis de la lectura es una operación cognitiva en tanto puesta en acción de un conocimiento y a su vez fuente de conocimiento. Finalmente, como sostuvo Iser, las ficciones resultan una necesidad antropológica del ser humano.

Las ideas esbozadas en este texto permiten explorar el aspecto lingüístico y semiótico del derecho sin abandonar la perspectiva crítica. A tal tarea me he abocado en mis investigaciones de los últimos veinte años. Algunos de los resultados pueden encontrarse en Cárcova (2008a, 2008b, 2018 y 2020); Cárcova, Douglas y Ruiz (2014), entre otros. 


\section{REFERENCIAS}

Borges, J. L. (1974). El Aleph. Emecé.

Cárcova, C. M. (2008a). Derecho y narración. En Karam, A., Magalhães, R. y Copetti, A. (orgs.), Direito \& Literatura: ensaios críticos (pp. 11-20). Livraria do Advogado.

Cárcova, C. M. (2008b). Ficción y verdad en la escena del Derecho. En Calvo, J. (ed.), Implicación Derecho Literatura: contribuciones a una teoría literaria del derecho (pp. 283-298). Comares.

Cárcova, C. M. (2018). Acerca del concepto de «posverdad». Anamorphosis. Revista Internacional de Direito e Literatura, 4(1), 5-16.

Cárcova, C. M. (ed.). (2020). Semiótica y Derecho. Astrea.

Cárcova, C. M., Douglas, J. y Ruiz, A. (2014). La letra y la ley. Ministerio de Justicia y Derechos Humanos de la Nación. 